\title{
Optimal Role of the Nephrologist in the Intensive Care Unit: An Intensivist's Opinion
}

\author{
David J.R. Morgan \\ Department of Intensive Care Medicine, Fiona Stanley Hospital, Murdoch, WA, Australia
}

\section{Dear Editor}

It is with intrigue I read the article by Askenazi and colleagues in Blood Purification 2017;43:68-77. Notwithstanding the variations in practices across different countries and health systems and that nephrologists are highly skillful doctors, I could not help but feel this article reads like a position statement posturing for greater control within the intensive care environment rather than a concerted document defining realistic mechanisms for improved outcomes. This manuscript has a generic template, is Americo-centric and has foregone meaningful clinical content for an overabundance of corporate governance style verbiage like "quality" (24 times), "multidisciplinary" (9 times) and "collaboration" (5 times). The apparent absence of intensive care authorship in a document belies the acclaimed multidiscipline approach, while the espoused roles of leadership, education and being a clinician are qualities that apply to all disciplines. None of the qualities listed in this document are specific to nephrologists and the authors fail to segregate the skill set unique to their specialty that obligates an increased role in intensive care. Similarly, the claim that critical care nephrology is an established specialty is both unfounded and self-promoting. At best, critical care nephrology is a niche area of expertise where decisive clinical advances in the past decade have been limited.
The intensivists' role in acute kidney injury and renal replacement therapies has been born out of 2 harsh realities of modern medicine. First, patients with multi-organ failure are best looked after by intensive care doctors and nurses. So successful has the critical care model been that our medical and surgical colleagues have relinquished all but the most stable of ward patients to our care. Intensivists, by our very namesake, are trained to manage multi-system failures more often than any other specialty and thus have the greatest understanding of multisystem interdependency, pathophysiology and prioritisation. Given that the vast majority of acute kidney injury is secondary to multiple organ failure, it is the intensivist who is best placed to manage this syndrome. However, probably the most pertinent observation is that sick patients get better when senior, experienced clinicians and nurses review them on a regular basis - not just once or twice a day, after clinic, or at the end of a ward round. The PROMOTE, PROMISE and the ARISE trials all demonstrated that "prescription" medicine does not absolve the clinician of reviewing their patients [1-3]. The intensivist's expertise has grown to not only include renal replacement therapies but also include performing echocardiography, inserting ECMO cannulas and heading medical emergency response teams. All these have evolved out of the lack of provision of these services by their traditional stakeholders during crucial out-of-hour time periods. The ATN and RENAL Trials provide some interesting insights to this point. In Australasia where the intensivist oversees the renal replacement therapy, patients were enrolled into the RENAL Study, on average, within 18-20 h of ICU admission with a $44.7 \% 90$-day mortality [4]. In America, where nephrologists are far more influential, on average, it was 6.46.9 days before patients were randomised into the ATN Trial with a 52.3\% 60-day mortality [5].

I have been fortunate enough to work alongside, and be taught by, many outstanding nephrologists. They have a crucial role to play in patient care but until the discipline is prepared to provide $24 / 7$ senior bedside reviews and assume out-of-hours responsibility, then intensivists must remain the driving clinicians behind timesensitive acute kidney injury management in the intensive care unit.

\section{Disclosure Statement}

I declare that I have no ethical or pecuniary interests that would conflict with the production of this manuscript.

\section{Financial Sources}

The author has received no financial or honorary support in the past 2 years.

\section{KARGER}

(c) 2017 S. Karger AG, Basel

E-Mail karger@karger.com

www.karger.com/bpu
David J.R. Morgan

Staff Specialist, Department of Intensive Care Medicine

Fiona Stanley Hospital, 11 Robin Warren Dr

Murdoch, WA 6150 (Australia)

E-Mail davidintoronto2004@ hotmail.com 


\section{References}

1 ARISE Investigators; ANZICS Clinical Trials Group, Peake SL, Delaney A, Bailey M, Bellomo R, Cameron PA, Cooper DJ, Higgins AM, Holdgate A, Howe BD, Webb SA, Williams P: Goal-directed resuscitation for patients with early septic shock. N Engl J Med 2014;371:1496-1506.

2 ProCESS Investigators, Yealy DM, Kellum JA, Huang DT, Barnato AE, Weissfeld LA, Pike F, Terndrup T, Wang HE, Hou PC, LoVecchio F, Filbin MR, Shapiro NI, Angus DC: A randomized trial of protocol-based care for early septic shock. N Engl J Med 2014;370:16831693.

3 Mouncey PR, Osborn TM, Power GS, Harrison DA, Sadique MZ, Grieve RD, Jahan R, Harvey SE, Bell D, Bion JF, Coats TJ, Singer M, Young JD, Rowan KM; ProMISe Trial Investigators: Trial of early, goal-directed resuscitation for septic shock. N Engl J Med 2015; 372:1301-1311

4 RENAL Replacement Therapy Study Investigators, Bellomo R, Cass A, Cole L, Finfer S, Gallagher M, Lo S, McArthur C, McGuinness
S, Myburgh J, Norton R, Scheinkestel C, Su S: Intensity of continuous renal-replacement therapy in critically ill patients. N Engl J Med 2009;361:1627-1638.

5 VA/NIH Acute Renal Failure Trial Network, Palevsky PM, Zhang JH, O'Connor TZ, Chertow GM, Crowley ST, Choudhury D, Finkel K, Kellum JA, Paganini E, Schein RM, Smith MW, Swanson KM, Thompson BT, Vijayan A, Watnick S, Star RA, Peduzzi P: Intensity of renal support in critically ill patients with acute kidney injury. N Engl J Med 2008;359:7-20. 